\title{
Unusual cause of severe toxic methemoglobinemia in an infant: a case report
}

\author{
Asma Bouziri • Ammar Khaldi • Khaled Menif • \\ Nejla Ben Jaballah
}

Received: 16 September 2009 / Accepted: 26 November 2009/Published online: 27 February 2010

(C) Springer-Verlag London Ltd 2010

\begin{abstract}
Toxic methemoglobinemia is an uncommon blood disorder induced by exposure to certain oxidizing agents and drugs. In severe cases, this condition may rapidly lead to major cardiopulmonary compromise and constitutes an emergency requiring prompt recognition and early management. We report an unusual case of severe toxic methemoglobinemia following wide cutaneous application of a pomade containing benzocaine, resorcin, and oxyquinoline $\left(\right.$ Nestosyl $\left.^{\circledR}\right)$ in an infant.
\end{abstract}

Keywords Benzocaine - Resorcinol · Oxyquinoline · Cutaneous administration $\cdot$ Methemoglobinemia .

Methylene blue

\section{Introduction}

Methemoglobinemia is a rare blood disorder, characterized by abnormal levels of oxidized hemoglobin that cannot bind to and transport oxygen [1,2]. The clinical picture is characterized by acute cyanosis and low oxygen saturations on pulse oximetry but normal oxygen saturation on arterial blood gas analysis [1]. When untreated, methemoglobinemia can lead to major cardiopulmonary compromise, neurologic sequela, and even death [2]. Thus, knowledge

Informed consent was obtained from parents before the submission of this article.

The views expressed in this paper are those of the author(s) and not those of the editors, editorial board or publisher.

A. Bouziri $(\bowtie) \cdot$ A. Khaldi $\cdot$ K. Menif $\cdot$ N. B. Jaballah

Paediatric Intensive Care Unit, Children's Hospital of Tunis,

Tunis, Tunisia

e-mail: asma.bouziri@yahoo.fr of this potentially life-threatening condition is essential for clinicians. This report describes an original case of toxic methemoglobinemia induced by wide cutaneous application of a pomade containing benzocaine, resorcin, and quinoline (Nestosyl ${ }^{\circledR}$ ) in a 16-month-old boy. To our knowledge, this cause and route of intoxication has not been previously reported in the literature.

\section{Case report}

A previously healthy 16-month-old boy presented to our emergency department for sudden development of cyanosis. On physical examination, the infant was agitated and unconscious (Glasgow Coma Scale $=12 / 15$ ), with a $38^{\circ} \mathrm{C}$ fever, a low oxygen saturation of $76 \%$, under $31 / \mathrm{min}$ of oxygen through nasal cannulae. His hemodynamic state was unstable with a heart rate of $200 \mathrm{bpm}$, a prolonged capillary refill time, and weak pulses. Besides, the patient presented widespread lesions of molluscum contagiosum on the anterior face of the thorax and the limbs. The infant was immediately intubated and mechanically ventilated with vascular filling ( $20 \mathrm{ml} / \mathrm{kg}$ of normal saline $0.9 \%$ ). The cyanosis was refractory to oxygen $\left(\mathrm{FiO}_{2}=1\right)$. The chest radiograph was normal and particularly eliminated a pulmonary barotrauma. The echocardiogram was normal. An arterial blood gas analysis revealed pH: 7.57, $\mathrm{PaO}_{2}: 157.4 \mathrm{mmHg}, P C O_{2}: 12.5 \mathrm{mmHg}$, $\mathrm{HCO}_{3}{ }^{-}: 11.6 \mathrm{mmol} / \mathrm{l}$, oxygen saturation $\left(\mathrm{SatO}_{2}\right): 99.7 \%$, and a methemoglobin level at $50.6 \%$ of total hemoglobin. Treatment of methemoglobinemia was then instituted using a methylene blue $1 \%$ solution $(10 \mathrm{mg} / \mathrm{ml})$ with a loading dose of $2 \mathrm{mg} / \mathrm{kg}$ administered intravenously over $5 \mathrm{~min}$ followed by $1 \mathrm{mg} / \mathrm{kg}$ twice daily. The parents were questioned about the different drugs and chemicals received recently by the infant. We found then the notion of 
automedication, $24 \mathrm{~h}$ previously, by Nestosyl ${ }^{\circledR}$ pomade with wide cutaneous application on the lesions of molluscum contagiosum and consumption of about half of a tube. After ruling out the other acquired causes of methemoglobinemia, and with a high degree of suspicion, methemoglobinemia was considered to be secondary to the wide cutaneous application of this pomade containing three components causing this complication: benzocaine, resorcin, and 8-hydroxyquinoline. Under methylene blue therapy and mechanical ventilation, the clinical course was favorable with rapid improvement of cyanosis, neurologic status, and hemodynamic state. Twenty-four hours later, methemoglobin levels decreased to $9.8 \%$. The patient was weaned from mechanical ventilation on day 2 and discharged on day 3 of his admission to the pediatric intensive care unit.

\section{Comments}

Methemoglobin is formed when the iron in hemoglobin is oxidized from ferrous $\left(\mathrm{Fe}^{2+}\right)$ to ferric $\left(\mathrm{Fe}^{3+}\right)$ state. Once formed, the molecule loses its ability to bind oxygen and also interferes with oxygen delivery to the tissues. The diagnosis of methemoglobinemia should be suspected in any patient with unexplained cyanosis and discordance between low oxygen saturation on pulse oximetry and normal blood gas concentrations of oxygen. The measurement of methemoglobin levels on arterial blood sampling is necessary to confirm the diagnosis [1]. Patients may appear cyanotic when their methemoglobin level exceeds $15 \%$ and generally become symptomatic when this level exceeds $30 \%$. Common symptoms are anxiety, dizziness, headache, tachycardia, arrhythmias, and confusion. When the level of methemoglobin exceeds $50 \%$, dyspnea, acidosis, heart failure, seizures, coma, and death can occur [1]. Our patient had a high level of methemoglobin above $50 \%$ explaining the severity of his clinical presentation. However, the clinical course was favorable under treatment. In fact, treatment of toxic methemoglobinemia is effective, if started promptly, and includes oxygenotherapy, discontinuation of causative medications, and intravenous administration of the antidote methylene blue $[1,2]$. Methemoglobinemia can be acquired, induced by exposure to certain oxidizing agents and drugs, or hereditary, related to deficiency of one of the enzymes necessary for reduction of methemoglobin to hemoglobin or to the presence of an abnormal hemoglobin resistant to reduction [2]. In our case, toxic methemoglobinemia was induced by wide cutaneous application of Nestosyl ${ }^{\circledR}$ pomade. This drug is a local antipruritic indicated for the symptomatic treatment of insects' bites. It is an overthe-counter medication but its use is prohibited in children under the age of 12 years. Its application on wide cutaneous surfaces and on deep cutaneous lesions is also prohibited. Nestosyl ${ }^{\circledR}$ contains butoform, benzocaine, resorcin, and 8hydroxyquinoline: the latter three can induce methemoglobinemia [3]. After review of the literature, we found only one case of methemoglobinemia induced by Nestosyl ${ }^{\circledR}$ after accidental ingestion [3] and five cases of methemoglobinemia induced by the association of two or three of these components [3-7]. Benzocaine is a local anesthetic commonly used for a variety of invasive procedures and constitutes the main component in a wide variety of creams and gels used for analgesia and anesthesia [8]. Since the first reported case of benzocaine-induced methemoglobinemia in 1950 , there have been approximately 95 cases reported in the literature [2, 8-11]. Resorcin and 8-hydroxyquinoline are a part of the composition of several drugs because of their antiseptic effects. They were less frequently incriminated in cases of methemoglobinemia than benzocaine $[3-7,12]$. Occurrence of methemoglobinemia via a transcutaneous route is also uncommon. Approximately six cases have been reported in the literature. The majority of them were induced by a eutectic mixture of local anesthetics (EMLA) cream and occurred in newborns and infants [13-15]. In our case, the automedication by Nestosyl ${ }^{\circledR}$ with unawareness of the potential risks and the limitations of use of this treatment caused methemoglobinemia: a potentially life-threatening complication. Thus, it is important to recognize possible drug reactions and to educate parents about the potential risks of treatment with over-the-counter medications, especially in neonates and infants [3].

\section{Conclusion}

This report illustrates an original case of toxic methemoglobinemia occurring in a 16-month-old infant after wide cutaneous application of a pomade containing benzocaine, resorcin, and hydroxyquinoline and demonstrates the possibility of the occurrence of severe systemic effects of drugs after wide cutaneous application especially in neonates and infants. It is thus important to educate parents about the potential risks of dermatological treatments, especially in young children.

Conflicts of interest The authors declare that they have no conflict of interest ordisclosures.

\section{References}

1. Jaffery Z, Ananthasubramaniam K (2008) A rare side effect of transesophageal echocardiography: methemoglobinemia from topical benzocaine anesthesia. Eur J Echocardiogr 9:289-290 
2. Kwok S, Fischer JL, Rogers JD (2008) Benzocaine and lidocaine induced methemoglobinemia after bronchoscopy: a case report. J Med Case Reports 2:16

3. Autret E, Forveille-Fournier E, Marchand S, Jonville AP, Ramponi N (1989) Methemoglobinemia after accidental Nestosyl ingestion (in French). Arch Fr Pediatr 46:271-272

4. Currie JL, Mott LA, Pennisi SC, Smith BD, Smith RP (1997) Potential for an external vaginal antiitch cream containing benzocaine to cause methemoglobinemia in healthy women. Am J Obstet Gynecol 176:1006-1008

5. Tush GM, Kuhn RJ (1996) Methemoglobinemia induced by an over-the-counter medication. Ann Pharmacother 30:1251-1254

6. Buquet S, Driencourt JB, La Condamine S, Cannamela A, Szymanovicz A, Carton MJ (1987) Toxic methemoglobinemia caused by a gingival lotion containing benzocaine and resorcin (in French). Ann Pediatr (Paris) 34:339

7. Blondet P, Le Roux P, Schandelong A, Legueult LC, Laine G (1985) Methemoglobinemia and acute toxic hemolytic anemia caused by gingival lotion with a benzocaine and resorcinol base (in French). Presse Med 14:1757

8. Birchem SK (2005) Benzocaine-induced methemoglobinemia during transesophageal echocardiography. J Am Osteopath Assoc 105:381

9. Kane GC, Hoehn SM, Behrenbeck TR, Mulvagh SL (2007) Benzocaine-induced methemoglobinemia based on the Mayo
Clinic experience from 28478 transesophageal echocardiograms: incidence, outcomes, and predisposing factors. Arch Intern Med 167:1977-1982

10. Vallurupalli S, Das S, Manchanda S (2009) Infection and the risk of topical anesthetic induced clinically significant methemoglobinemia after transesophageal echocardiography. Echocardiography [Epub ahead of print]

11. Chung NY, Batra R, Itzkevitch M, Boruchov D, Baldauf M (2008) Severe methemoglobinemia linked to gel-type topical benzocaine use: a case report. J Emerg Med [Epub ahead of print]

12. Alvarez-Coca J, García S, Gómez P, Quevedo E, Villar A, Ruza F (1985) Methemoglobinemia caused by resorcinol (in Spanish). An Esp Pediatr 23:305-307

13. Eekhof JA, de Kanter JS, Assendelf WJ, Krijger JM, Bouvy ML, Cheung KC (2006) Coma in a child after treatment with the 'magic salve' lidocaine-prilocaine cream (in Dutch). Ned Tijdschr Geneeskd 150:2729-2730

14. Shachor-Meyouhas Y, Galbraith R, Shavit I (2008) Application of topical analgesia in triage: a potential for harm. J Emerg Med 35:39-41

15. Elsner P, Dummer R (1997) Signs of methaemoglobinaemia after topical application of EMLA cream in an infant with haemangioma. Dermatology 195:153-154 